\title{
A dimensão simbólica dos conflitos: moradores de favela e polícia
}

The symbolic dimension of the conflict: residents

from favelas and police

\section{Marcus Cardoso}

\section{(2) OpenEdition}

\section{Journals}

\section{Edição electrónica}

URL: http://journals.openedition.org/aa/392

DOI: $10.4000 /$ aa.392

ISSN: 2357-738X

\section{Editora}

Programa de Pós-Graduação em Antropologia Social (UnB)

\section{Edição impressa}

Data de publição: 1 junho 2013

Paginação: 167-190

ISSN: 0102-4302

\section{Refêrencia eletrónica}

Marcus Cardoso, «A dimensão simbólica dos conflitos: moradores de favela e polícia », Anuário Antropológico [Online], v.38 n. 1 | 2013, posto online no dia 01 outubro 2013, consultado o 28 abril 2021. URL: http://journals.openedition.org/aa/392 ; DOl: https://doi.org/10.4000/aa.392

\section{(c) $($ ) $\odot \odot$}

Anuário Antropológico is licensed under a Creative Commons Atribuição-Uso Não-Comercial-Proibição de realização de Obras Derivadas 4.0 International. 


\section{A dimensão simbólica dos conflitos: moradores de favela e polícia}

Marcus Cardoso

UNIFAP

Depois de alguns meses ouvindo as recorrentes reclamações que os moradores das favelas do Pavão-Pavãozinho e Cantagalo direcionavam aos policiais, dei-me conta de um aspecto presente na estrutura das narrativas que, até então, havia passado despercebido. Refiro-me à existência de uma conexão entre as queixas confidenciadas por aqueles com quem mantive relações sociais durante minha pesquisa de campo e concepções de direitos. Ou seja, para meus interlocutores, falar das instituições policiais e seus agentes implicava, de forma explícita ou implícita, falar de concepções locais sobre justiça e direito. Meu interesse neste artigo é justamente abordar a correlação entre concepções de direitos, insatisfações com a polícia e demandas por respeito, tal como me foram apresentadas por eles.

A esta altura convém deixar claro para os eventuais leitores que não é meu interesse discutir questões literais sobre a Carta Constitucional no que se refere aos direitos de cidadania e ao papel das instituições policiais em sociedades democráticas. Tampouco trata-se de apontar a existência ou não de leituras equivocadas sobre direitos ou se os agentes do Estado e os cidadãos estão plenamente cientes dos deveres e direitos a serem considerados na relação entre as partes. Ao tratar de direitos e instituições policiais, busco privilegiar em minha análise o ponto de vista nativo, interessado em como a relação com os policiais e os direitos são vivenciados e ganham sentido localmente. Um empreendimento como este exige atenção cuidadosa aos depoimentos dos meus interlocutores. Ao proceder desta forma é possível encontrar eventuais similaridades e recorrências em suas narrativas e, a partir disso, alcançar a estrutura significativa que articula suas experiências.

Esta opção não é aleatória. Não é novidade para a antropologia que o Direito, como um conjunto de normas que visa regular o comportamento dos membros de uma sociedade é um saber local (Geertz, 2000). Códigos, leis etc. refletem uma dada concepção de mundo. Soma-se a isto que, mesmo dentro de uma 
sociedade, o Direito está sujeito a múltiplas significações (Cardoso de Oliveira, 2011a). O código pode ser único, mas como ele é vivido e pensado varia (ou pode variar) de acordo com o grupo social acompanhado. Por conseguinte, as insatisfações e as queixas provenientes das concepções locais de justiça e direitos só podem ser devidamente compreendidas se considerarmos os valores acionados nos contextos das relações sociais conflituosas, dentro daquilo que vem sendo classificado por Cardoso de Oliveira de dimensão simbólica do direito (2011a). ${ }^{1}$

Tendo isso em mente, proponho desenvolver este artigo da seguinte forma: 1.explicitar o que os moradores têm a dizer sobre a polícia e sobre a forma como seus agentes atuam nas favelas; 2.demonstrar a existência da articulação entre a visão sobre a polícia e concepções locais de direitos; 3. e, por último, analisar esta articulação a partir da discussão sobre reconhecimento - entendido aqui como dimensão simbólica do direito - por acreditar que através dela possamos compreender, desde o ponto de vista dos demandantes, os motivos das insatisfações que geram conflitos.

\section{As favelas}

A poucos minutos da Nossa Senhora de Copacabana e Vieira Souto, avenidas que cortam as duas mais famosas orlas do Rio de Janeiro, encontram-se as favelas do Cantagalo e Pavão-Pavãozinho. Seus habitantes convivem cotidianamente com as vantagens e as desvantagens provenientes da localização geográfica privilegiada na qual se encontram. O fato de estas avenidas estarem próximas ao mar, rodeadas de inúmeros hotéis de luxo e cercadas por uma população com bom poder aquisitivo, faz delas um importante e lucrativo ponto de venda de drogas frequentado por turistas e habitantes dos bairros próximos. Não por acaso, ao longo dos anos, elas foram palco de diversas disputas entre facções rivais que ambicionavam controlar o comércio ilícito na região. ${ }^{2}$

Os primeiros registros indicam que a ocupação teve início com a formação do Cantagalo, na primeira década dos 1900. Posteriormente, a ocupação estendeu-se pela encosta do morro, surgindo o Pavão-Pavãozinho a partir dos anos de 1920 (Seth, 1985). Desde a década de 1950 as favelas foram tratadas pelos governos que se sucederam como um complexo, alvo de políticas públicas conjuntas, o que, eventualmente, gerava desconforto entre os moradores das duas favelas. Como esta é uma questão duplamente relevante, tanto para os moradores quanto para a forma como estruturo minha análise, eu me deterei um pouco nela. Minha intenção é demonstrar que, apesar das diferenças inegáveis entre as duas favelas, é perfeitamente possível tratar das concepções de direitos e de justiça elaboradas por eles de forma conjunta. 
Como apontei, ao longo do século passado chegando até os dias de hoje, o Poder Público atuou e atua nas favelas concebendo-as como um complexo. Durante as décadas de 1960 e 1970, as primeiras bicas d'água foram instaladas, fazendo com que os residentes das duas favelas não tivessem mais a necessidade de buscar água no asfalto. Também durante esse período, a Light, companhia de energia elétrica, passou a operar tanto no Cantagalo quanto no Pavão-Pavãozinho. A partir da década de 1980, no governo de Leonel Brizola, as duas favelas receberam maior intervenção do estado, com a construção de um $\mathrm{CIEP}^{3}$ no Cantagalo (que atendia às duas localidades) e melhorias no sistema de abastecimento de água e esgoto (Ribeiro, 2003). A percepção das favelas como complexo foi mais uma vez reafirmada quando da instalação do Grupamento de Policiamento de Áreas Especiais (GPAE) em 2000, e do projeto Criança Esperança em 2001, assim como na implementação do Programa de Aceleração do Crescimento (PAC) em 2007, e na chegada da Unidade de Polícia Pacificadora (UPP) em 2009. ${ }^{4}$

A história e a identidade do Pavão-Pavãozinho guardam estreita relação com a migração de indivíduos da região Nordeste do país. No caso do Cantagalo, a ocupação ocorreu a partir do deslocamento de famílias oriundas de regiões do interior do Estado do Rio de Janeiro e de Minas Gerais. Já demonstrei em outro momento que, apesar de ocuparem o mesmo terreno rochoso e suas fronteiras serem de difícil percepção para aqueles que as visitam pela primeira vez, as duas favelas possuem histórias, organização política comunitária e identidades distintas (Cardoso, 2003, 2010). Seus moradores fazem questão de marcar as diferenças, ressaltando os aspectos positivos da sua favela e os negativos dos vizinhos, inclusive utilizando categorias de acusação e desqualificação uns dos outros. Desse modo, não resta dúvida sobre a existência de um "nós" em contraponto a "eles", quando se trata de falar de si, da sua história, do seu cotidiano e da relação com seus vizinhos. Todavia, o quadro modifica-se quando a relação é com as ONGs e/ ou os órgãos públicos. Diante de situações que envolvem demandas por serviços ou cooptação de projetos sociais é comum que as lideranças locais articulam-se, agindo conjuntamente. Em casos assim o "nós” engloba as duas favelas.

Mas não é simplesmente por isso que considero poder tratar suas narrativas conjuntamente. Do meu ponto de vista, não há como ignorar a existência de uma percepção compartilhada sobre determinados temas, sendo a polícia um deles. As narrativas assemelham-se muito em sua estrutura, as principais acusações contra os agentes são as mesmas. Entre os moradores das duas favelas a categoria respeito ocupa lugar central nas queixas e nas demandas por consideração de direitos. Quando trata-se de determinados temas, é possível identificar 
a existência de compartilhamento de visões de mundo, opiniões e formas de estruturar suas narrativas. Esta afirmação, fundamental para a minha proposta neste artigo, carrega consigo duas implicações: uma delas é supor que, apesar das diferenças, no que concerne à polícia e às suas concepções de justiça, eles atribuem significado às suas experiências a partir de um mesmo referencial simbólico; a segunda é que, justamente por isso, o pesquisador pode tratar de forma conjunta e articulada as suas narrativas. ${ }^{5}$

\section{A polícia e o desrespeito}

A visão que os moradores têm sobre a polícia guarda relação direta com suas experiências concretas. As práticas policiais apontadas como problemáticas são aquelas que, de alguma maneira, trazem transtornos ao seu cotidiano, sendo vivenciadas como um ato de desrespeito aos seus direitos e/ou desconsideração à pessoa. ${ }^{6}$ Grosso modo, as reclamações que surgem com maior frequência podem ser dividas em três grupos: acusações de corrupção; uso de violência abusiva que pode ou não resultar em execução; e as incursões policiais, que ameaçam a integridade física dos moradores. Nesta seção trago alguns depoimentos que tratam destes temas.

Quando uma ou duas viaturas da Polícia Militar percorriam as ruas que dão acesso às favelas, era comum escutar alguém dizendo: "hoje é dia do pagamento”. A expressão - carregada com forte conteúdo de ironia e resignação - exprime bem o juízo que tinham acerca da polícia. A percepção era de que os policiais que atuavam nas duas favelas mantinham um acordo corrupto com o "movimento". 7

A polícia não faz nada porque tá envolvida. Então deixa eles [o movimento] fazerem o que querem porque o dinheiro já tá garantido... Todos eles [os policiais] querem uma grana extra.

“Não faz nada" - tal como foi declarado por um morador - implica dizer que o grupo local pode manter o comércio de drogas ilícitas, exercendo o controle coercitivo sobre os demais habitantes das favelas sem que se sintam ameaçados por uma possível interferência policial. Destarte, casos de abusos, ameaças à vida e humilhações cometidos por traficantes tinham a responsabilização compartilhada com os policiais, visto que estes últimos se omitiam, abrindo o caminho para que estas práticas ocorressem. ${ }^{8}$

A reação ao assassinato de um adolescente, ocorrido dentro da favela do Pavão-Pavãozinho pelas mãos do "movimento", é ilustrativa. Enquanto estava 
realizando minha pesquisa de campo, um rapaz, membro de uma família católica praticante que morava há mais de 30 anos na favela, viciado em cocaína e com dívida financeira com o movimento, foi torturado, executado e incinerado. O rapaz não era apenas um consumidor endividado. Até pouco tempo antes de sua morte ele era um "soldado do tráfico". Seus amigos de infância, vizinhos e familiares sabiam do seu envolvimento e da sua dívida. Apesar disto, após a execução, parte da indignação destas pessoas foi dirigida aos policiais que costumavam trabalhar na favela.

À época do ocorrido tive a oportunidade de conversar com a mãe do rapaz. Apesar de não ignorar as escolhas equivocadas do filho e a ação do grupo criminoso, ela culpou a polícia pelo ocorrido. Ao não enfrentar o "movimento", permitindo a manutenção do comércio ilícito de drogas, a polícia havia contribuído decisivamente para a morte do rapaz. Esta opinião era compartilhada pelas pessoas próximas e a responsabilização pelo assassinato quase sempre se deslocava da má escolha de M., ou da ação violenta do movimento, para a não intervenção policial.

Que polícia é essa que deixa o movimento funcionar? Se está aqui, não pode deixar as coisas acontecerem como foi com o M.. Todo mundo sabia que ele ia morrer, todo mundo. O garoto chegou, ficou aqui não sei quanto tempo sabendo que a qualquer hora ia morrer, e ninguém fez nada. Mas quem tinha que fazer era a polícia.

Do que adianta esses policiais aqui se as drogas continuam à solta. Esse pessoal continua mandando, fazendo o que quer e a polícia não faz nada.

Para os moradores, o suposto acordo corrupto é o responsável pela omissão dos policiais não apenas em casos como o do rapaz assassinado, mas também nas outras modalidades de intimidação e violência física. Muitas vezes, em suas queixas, eles cobram da polícia o cumprimento daquilo que acreditam ser o seu papel: proteger as "pessoas de bem". Não fazê-lo, omitir-se permitindo que o "movimento" atue, acaba provocando uma sensação que poderíamos chamar aqui de abandono e de desconsideração. A presença da polícia não estava associada à garantia da integridade física ou à garantia da segurança, tampouco estava associada à repressão à comercialização de drogas ilícitas ou à busca dos indivíduos que cometeram delitos, mas sim era parte do acordo que permitia o controle do local e que prejudicava o cotidiano daqueles que não pertenciam ao movimento. ${ }^{9}$ Isso fazia com que os moradores aproximassem simbolicamente policiais e grupo criminoso. 
Isso é um acordo de interessados, um acordo de boa convivência. Você me dá um dinheiro e eu não te perturbo. Então é assim, quando uns tão num lugar os outros não aparecem pra não ter confusão, porque se aparecer no mesmo lugar, pode acontecer algum mal-entendido, sabe?! Então, no final das contas, é tudo a mesma coisa, só que uns usam farda e outros não.

Agora, esses frustrados [os policiais], com eles não tem conversa. Eles botam pra quebrar e não querem nem saber se você tá envolvido. Não dá pra confiar mesmo. Até porque os dois lados são a mesma coisa...Toda hora tão aí para pegar dinheiro... Eles chegam botando para quebrar só para mostrar que está na hora de receber.

Além da corrupção, denúncias de violência cometida por policiais são recorrentes. Grosso modo, as práticas que se enquadram nesta categoria são de duas ordens: os abusos de autoridade com a utilização de violência excessiva e os homicídios, sobretudo aqueles nos quais havia a suspeita de execução. Um exemplo da violência referida pelos moradores e que classifico como prática de violência abusiva ocorreu em 2001, durante os festejos de Carnaval no Pavão-Pavãozinho, quando policiais militares agrediram três jovens e forjaram um flagrante de posse de drogas com o intuito de incriminá-los. Temendo a eminência de um desfecho dramático que, na percepção dos presentes, provavelmente culminaria com a execução sumária dos rapazes, alguns moradores seguiram os policiais até o posto de policiamento e por lá permaneceram com o intuito de constrangê-los. ${ }^{10}$

A gente tinha ido ver o desfile das campeãs com um pessoal amigo lá da Rocinha. Tudo normal. Na volta tava eu, minha esposa e a irmã dela, que também mora aqui na favela, subindo pra cá, quando vimos uma muvuca ali no Serafim [nome de uma localidade no interior da favela]. De longe, já dava pra ver que não era boa coisa, tinha um pessoal falando alto, gritando, sei lá. Eu pensei que fosse essas brigas de bêbedo, que é comum no carnaval, e continuamos andando. Quando chegamos ali no Serafim, nós vimos, nós e umas outras dez pessoas, os policiais [que] estavam dando uns tapas em uns garotos, dizendo que eles iam ver só. Tinha um pessoal gritando, dizendo que eles não tinham feito nada, que eles não eram bandidos, mas não adiantou, os policiais resolveram descer com eles até a Praça do Caô, onde tem aquela base deles, e aí foi todo mundo junto com medo que acontecesse algo pior com os três. Eu mandei elas irem pra casa e desci com o pessoal. 
Posteriormente, foi dito que a abordagem destes rapazes não foi aleatória. Os policiais desconfiavam da participação deles no movimento, e os dois grupos vinham se estranhando nos últimos meses, aumentando a animosidade entre as partes. Com a favela esvaziada devido aos festejos, quando os jovens e os policiais se encontraram, surgiu a oportunidade do "acerto de contas".

Para os moradores, nem todos tiveram ou têm a sorte dos três jovens que, em função da providencial intervenção daqueles que lá estavam, fugiram de um destino funesto. Considerando a reação local no caso descrito acima, não surpreende que as execuções também tenham a responsabilização atribuída aos policiais, ocupando um lugar de destaque no repertório acusatório local. Segundo a percepção que têm da polícia, os assassinatos com características de execução podem vitimar qualquer pessoa: homem ou mulher, criança ou adulto, sejam elas pertencentes ao "movimento" ou sejam "trabalhadores". Ainda dentro deste universo de significação, os motivos que fazem com que os policiais ultrapassem os limites dos procedimentos legais transitam entrem o "acerto de contas" e - tal como me disse uma moradora - a "pura maldade”, expressão da perversidade e da violência dos policiais.

O "acerto de contas" é a motivação atribuída quando se trata de casos que envolvem indivíduos pertencentes ao "movimento", como, por exemplo, incapacidade de pagar extorsões ou o fracasso em uma suposta negociação corrupta entre os envolvidos. Também estão dentro do chamado "acerto de contas" casos em que indivíduos suspeitos da prática de pequenos furtos a lojas do bairro ou assalto a banhistas mobilizam a atenção e a ação dos policiais. Destarte, podemos entender que o "acerto de contas" é quando o assassinato de uma ou mais pessoas abrange o universo das relações entre policiais e pessoas envolvidas com alguma modalidade de crime. Aqui se faz necessário sublinhar que a categoria crime, assim como qualquer outra, ganha sentido local e não corresponde necessariamente ao previsto no Código Penal. O crime, neste contexto, guarda estreita relação com práticas de furtos, assaltos, venda de drogas e participação no "movimento", não sendo considerada prática criminosa, por exemplo, a comercialização de produtos piratas.

Algo bem diferente são as mortes das "pessoas de bem" e/ou "trabalhadores" com características de execução. É quando pessoas que não infringiram a lei, não cometeram crimes, não mantiveram relações consideradas promíscuas com o comércio ilegal de drogas local são assassinadas por policiais que o acontecido é vivenciado como ato ignominioso, um insulto moral (Cardoso de Oliveira, 2002). Paralelamente existe o medo, visto que situações como esta revelam que não há nada que eles possam fazer que os protejam de se tornarem vítimas. 
A percepção do seu caráter aleatório alimenta o medo e a desconfiança, visto que traz consigo a potencialidade de vitimar qualquer indivíduo, independente de qualquer coisa, fomentando assim a insatisfação local que, por vezes, torna-se pública através de protestos que buscam denunciar práticas criminosas cometidas por policiais.

A lista de acusações de execuções atribuídas a policiais é grande. Dentre os episódios mais lembrados, está o ocorrido em maio de 2000, quando, após uma ação no Cantagalo, cinco jovens apareceram mortos. Na época, a Polícia Militar sustentou que os policiais em serviço haviam sido alvejados e que, ao se defenderem, acabaram matando os rapazes na troca de tiros. Em contraste com esta versão, os moradores colocaram em dúvida o argumento que sustentava que a ação policial se configurava como legítima defesa.

[...] quando aconteceu a morte de vários rapazes no Cantagalo [...] tudo bem, é do crime, mas foram mortos, segundo as pessoas que estavam mais próximas, foi injustamente. Como pode um carro, um único carro, ser abordado por 14 pessoas que já estavam esperando esse carro [...] chegar esse carro e matar uma porção de pessoas, e não saiu sequer um tiro? Se estão esperando esse carro, o mais provável é que o carro seja atingido primeiro. Mas não. $\mathrm{O}$ policial consegue chegar, ir até onde estão essas pessoas, matar três ou quatro, mas nem com o carro e nem com os policiais acontece nada. A história está mal contada...

Caso semelhante ocorreu em novembro de 2003, na favela do PavãoPavãozinho, quando os moradores protestaram nas ruas de Copacabana acusando policiais de executar um indivíduo e da tentativa de executar outro. $\mathrm{O}$ episódio repercutiu nos órgãos de comunicação e o jornal $O$ Globo, na sua edição de 9 de novembro, publicou matéria intitulada "Rapaz é morto no PavãoPavãozinho”. Localmente este episódio foi visto como mais uma execução, enquanto a versão oficial sustentava que o homem havia sido morto em troca de tiros durante uma ronda preventiva. Em 2004, mais uma vez, os moradores das duas favelas se mobilizaram para protestar contra supostas execuções. Segundo o relato, um grupo de policiais abordou e rendeu dois homens no interior da favela do Pavão-Pavãozinho para, na sequência, executá-los com tiros pelas costas. O episódio foi relatado no dia 6 de março pelo jornal $O$ Globo com o seguinte título: "Testemunhas dizem que faxineiro implorou a PMs para não ser morto".

A violência policial e as execuções são reprováveis, independente da adesão ou não do indivíduo ao "movimento". Mas, como disse anteriormente, o 
sentimento de revolta e indignação adquire maiores proporções quando as vítimas são pessoas que não fazem parte do crime organizado. São agressões que, no entendimento local, revelam a incapacidade e/ou a recusa de reconhecer a diferenciação entre as "pessoas de bem" e os envolvidos com o crime. Justamente por isso, são vivenciados como desrespeito e humilhação.

Isso aí não tem jeito. Eles não querem saber se você faz parte [da quadrilha local] ou só está passando por ali na hora errada. Tratam todo mundo como bandido e não respeitam ninguém. Às vezes eles sabem que você não é do esquema, mas eles querem humilhar e te fazem passar vergonha, te desrespeitam na frente de qualquer um, não querem nem saber se teu filho está do lado e que vai ver o pai ser tratado como um porco. Eles não podem fazer isso. Não podem...

É todo dia. Nas outras coisas também, como humilhar a gente na hora de revistar ou quando fala. É bater, é roubar porque ninguém vai acreditar mesmo. É a palavra de favelado contra a do policial.

Falta apresentar o último conjunto de reclamações às quais aludi no começo desta seção. Refiro-me aos tiroteios e à maneira como as operações policiais são conduzidas dentro das favelas. A partir da década de 1980, o perfil do crime na cidade do Rio de Janeiro transformou-se, e os grupos que dominavam a comercialização das drogas passaram a organizar-se a partir das áreas pobres (Zaluar, 1985, 2010; Soares, 1996). Desde então, episódios de enfrentamentos entre grupos rivais que desejavam controlar determinados pontos de venda de drogas tornaram-se recorrentes, assim como as incursões policiais nas favelas. No Cantagalo e no Pavão-Pavãozinho não foi diferente. Como se percebe a partir das narrativas, episódios desta ordem fazem parte da história local. Viver nas favelas envolve uma parcela de risco que não é passível de cálculo, visto que não se sabe, ao certo, quando os confrontos explodirão. ${ }^{11} \mathrm{~A}$ incerteza é responsável pelo aumento da sensação de medo, tal como sugerem as falas a seguir:

Não gosto nem de falar nisso. Isso que você tá gravando é pra que mesmo? Olha pra onde isso vai parar, hein!... Quando um pessoal invadiu aqui, nesse caso que eu te falei, durante o dia eles avisavam todo mundo pra ir embora ou se trancar dentro de casa. Diziam: quem saísse ia morrer. Eles queriam o lugar vazio pra saber quem era que tava subindo. Eu não queria ir embora porque tinha as minhas coisas, minha televisão, minha geladeira, meu gás, mas 
também não dava pra ficar. Eu tentei ficar, na primeira noite parecia o fim dos tempos. No outro dia, quando já era quase noite, eles avisaram que ia acontecer novamente, e aí eu peguei as crianças e desci. Fiquei lá na Sá Ferreira com uma porção de gente. A comunidade toda desceu e dormiu na Sá Ferreira e nas outras ruas. Sabe, foram os piores dias da minha vida, mas fazer o quê, a gente não tem pra onde ir e ninguém dá um fim nisso. Só rezando mesmo.

[...] Mas o pior de todos foi o que aconteceu quando um pessoal lá da Mangueira decidiu tomar aqui. Aí não teve jeito! Rapaz, vou te dizer, isso não é vida não!

[...] A gente acorda com medo e dorme com medo... Só Jesus na causa.

Se a dificuldade de antever esses confrontos gera apreensão, a postura adotada pelos policiais potencializa os riscos. Segundo os moradores, nenhum tipo de precaução é adotada para preservar a integridade física das "pessoas de bem”. Assim como acontece com as outras queixas, a condução das operações policiais nas favelas do Cantagalo e do Pavão-Pavãozinho é vivenciada como demonstração de desrespeito com aqueles que trabalham e são pessoas de bem, e de despreocupação com a sua segurança e vida:"[...] O que eu quero dizer com isso é que bandido tem em todo lugar [...] O que acontecia era que se chegava de qualquer jeito, atirando sem querer saber quem estava no caminho e, depois que morria, era só dizer que era bandido”.

\section{Direitos, trabalhadores e impostos}

Os depoimentos apresentados até aqui apontam que o entendimento que os indivíduos têm dos seus direitos guarda relação direta com expectativas por tratamentos respeitosos e por demonstrações de cuidado. O primeiro podendo ser traduzido como tratamento digno que preserve a dignidade dos moradores, e o segundo, como a adoção de procedimentos que demonstrem a preocupação dos policiais coma sua segurança.

A expectativa de ser tratado como esperam não corresponde aos preceitos constitucionais que garantem o alcance universal dos direitos de cidadania. Não se trata de conceber que todos tenham direitos e devam ser tradados de forma igual, segundo o que é previsto na lei. Isto fica claro quando se percebe a presença recorrente de categorias como "pessoa de bem" e "trabalhador" nos depoimentos. Buscar os significados que estas e outras categorias ganham no contexto em que são acionadas permite aprofundar a reflexão para que se compreenda 
quais são as qualidades individuais capazes de preencher os requisitos necessários que tornam uma pessoa merecedora de consideração dos seus direitos. "Todos deveriam ter seus direitos respeitados, dizem os moradores das favelas do Cantagalo e do Pavão-Pavãozinho. Porém, existem aquelas pessoas que, em nenhuma hipótese, poderiam experimentar a violação dos seus direitos. É a adesão à "ética do trabalho" (que distingue a "pessoa de bem" do "marginal") que habilita o sujeito a ter seus direitos respeitados. Acioná-la para criticar a postura policial sublinha a sua diferenciação em relação àqueles que optaram por aderir ao "movimento", ao mesmo tempo em que, simbolicamente, coloca-os em condição de igualdade com as "pessoas de bem" das áreas nobres da cidade.

Mas quando é na Atlântica ou na Vieira Souto, aí é diferente. Não se atira porque não pode botar em risco um doutor ou a madame. Só se atira quando não tem jeito, não é?! Aí a polícia negocia, chama advogado, promete que não vai matar. Só pra não colocar em risco a vida. Por que com o morador do morro tem que ser diferente? Nós somos humanos também. A maioria aqui é gente que trabalha, que acorda cedo, que paga as contas e quer ser respeitado. Eu também quero que a polícia não ponha minha vida em risco.

E a gente também merece, não é só quem mora na [avenida] Atlântica que tem direito a sossego, que o governo tem que se preocupar. Lá tem bandido também, mas a polícia não chega atirando, não é verdade?!

A insatisfação com o procedimento policial fica evidenciada quando comparam a condução das operações nas duas favelas com as operações nas áreas nobres da cidade. Segundo entendem, quando os policiais atuam nesses lugares, cercam-se de cuidados de modo a não colocar em risco a integridade física das pessoas, lançando mão do uso da força, sobretudo no que se refere à utilização de armas de fogo, apenas usadas como último recurso. Para eles, os procedimentos adotados por policiais expressam que as diferenças nas abordagens derivam da percepção que opõe os moradores de favelas e os do asfalto, quando o que deveria operar é o reconhecimento da oposição entre "trabalhadores/pessoas de bem”, de um lado, e "traficantes/bandidos", de outro.

Passagens como "a maioria aqui é gente que trabalha”, que associam esta condição à expectativa de ser respeitado e de ter sua segurança considerada, aproximam os moradores das favelas daqueles que moram na Vieira Souto. Os que trabalham e não se associam ao crime deveriam ter seus direitos respeitados, independente da sua condição socioeconômica. Entretanto, a prática policial não 
reconhece esta aproximação, desconsiderando qualquer diferenciação que seja relevante a ponto de conduzir estratégias que não coloquem em risco a vida das "pessoas de bem".

A questão da consideração dos seus direitos não se encerra no reconhecimento da sua condição de "pessoas de bem". Foi durante minha última estadia no campo que percebi a inserção de um novo elemento nas narrativas sobre direitos e sobre polícia. Refiro-me à percepção difusa do respeito aos seus direitos como contrapartida, por parte do Estado, do status de contribuinte do erário público e/ou sujeito que paga suas contas.

Agora todo mundo paga luz, tem que pagar IPTU. Eu nunca deixo de pagar. Eu e a maioria das pessoas daqui. Então a gente tem que ser tratado direito, porque eu estou pagando igual a você e igual a qualquer um lá debaixo. Então, não deveria ter essa de mandar eu deitar no chão, me dar tapa na cara, só porque eu moro na favela.

Enquanto em 2001, 2002 e 2004 eu não havia presenciado uma única vez o acionamento desta categoria para reclamar da postura policial ou para demandar respeito aos direitos, em 2007 ela surgiu como uma questão a ser considerada. Neste ano foi anunciado que o Programa de Aceleração do Crescimento (PAC) implementaria obras de infraestrutura nas duas favelas, gerando discussões, ressuscitando alguns medos antigos de remoção, assim como velhas promessas de regularização das moradias. Desde 2001, os moradores das duas favelas conviviam com a possibilidade de remoções e realocações indesejadas com a chegada do Programa Favela-Bairro. ${ }^{12} \mathrm{Na}$ época, os representantes governamentais, em reuniões cercadas de muita tensão, tentavam dirimir o medo dos moradores dizendo que a partir do programa eles ganhariam documentos que lhes garantiriam aposse das suas casas. Os anos de convívio com a articulação da linguagem dos direitos e a possibilidade do reconhecimento da posse podem ter sido os responsáveis pela sua incorporação entre os locais, já que era com esta promessa que os representantes das diferentes esferas de governo apresentavam seus projetos.

É importante ressaltar que o pagamento de imposto ou da conta não correspondia necessariamente à dimensão formal do erário público, administrado pelo estado, o que não impedia que alguns moradores demandassem direitos através desta linguagem. Ao menos até 2007, nem os moradores do Cantagalo nem os moradores do Pavão-Pavãozinho haviam pago IPTU. Em contrapartida, o pagamento dos canais a cabo era destinado ao crime organizado local. ${ }^{13}$ Todavia, isso não impedia que a linguagem do "pagador" ou "contribuinte" fosse 
acionada. No meu ponto de vista, é uma situação que se assemelha muito ao que ocorre com a ética do trabalho. Dizer que é trabalhador como forma de reafirmar a sua recusa em aderir ao tráfico não implica a inserção no mercado formal ou legal de trabalho. Igualmente, a noção de contribuinte não corresponde ao significado estrito e formal do termo. Ainda que eu não tenha condições de afirmar, suspeito que no caso específico do IPTU, a sua presença em algumas narrativas fosse resultado das expectativas do que, supostamente, estava por vir. ${ }^{14}$

De toda maneira, também nestes casos, tal como ocorre quando acionam a adesão à ética do trabalho, as assertivas relacionavam-se às queixas sobre tratamento diferenciado dispensado por policiais.

Eu e minhas filhas trabalhamos duro. Nós pagamos tudo direitinho, luz, [TV] cabo. A diferença agora com o pessoal da rua é que a gente mora no alto e a polícia não respeita a nossa casa nem nossa vida. Nós pagamos igual a qualquer um, mas ainda somos tratados como bicho. Como bicho não, como gente da pior espécie, porque bicho todo mundo trata bem.

Como aludi anteriormente, a prerrogativa de ter seus direitos respeitados não se estende à totalidade dos habitantes das favelas. Segundo a percepção local, há pessoas que devem ser tratadas de forma que tenham seus direitos preservados - em que os abusos sejam considerados um atentado à sua dignidade e um sinal claro de discriminação por parte dos policiais - e há aqueles que, devido ao envolvimento com o movimento, estão sujeitos a se tornarem alvos de abusos. É importante que fique claro que não há apoio aos procedimentos abusivos de policiais contra as pessoas que pertencem ao grupo criminoso. Mas episódios desta ordem não são capazes de gerar o mesmo nível de indignação como aqueles que envolvem as "pessoas de bem". Isto porque optar pelo crime significa assumir o risco inerente à escolha. Da mesma forma que os moradores não entendem as agressões dos traficantes contra os usuários de drogas ou contra indivíduos que pertencem ao grupo rival como um atentado aos seus direitos e dignidade, também entendem que a relação entre polícia e tráfico envolve uma outra lógica. Os moradores distinguem valorativamente quem é do movimento e quem não é, e nesta distinção eles se colocam numa posição moralmente superior aos traficantes.

Essa distinção (que não é estática nem absoluta) encontra eco em outras localidades onde grupos criminosos que dominam o comércio de drogas estão presentes. Desde o trabalho de Alba Zaluar sobre a Cidade de Deus, ficou claro como as categorias locais "trabalhador" e "bandido" desempenham papel importante na 
construção da identidade em áreas dominadas por grupos criminosos (1985). A situação é semelhante nas favelas do Pavão-Pavãozinho e Cantagalo. Os moradores expressam seu desconforto com o não reconhecimento, por parte dos policiais, da distinção entre quem fez a escolha de aderir ao grupo criminoso e quem escolheu trabalhar. Em última análise, isto significa dizer que as "pessoas de bem" não deveriam ser objeto do mesmo tipo de tratamento dispensado ao "movimento".

[...] Agora, quando acontece com quem não tem nada a ver com esse rolo aí, é sacanagem. O sujeito trabalha pra sustentar a família e ainda é esculachado do nada. E vai fazer o quê?

[...] pra polícia só tem bandido aqui. Na verdade, eles sabem que não é assim, que tem muita gente trabalhadora que não faz nada errado, que não se mete com o crime. Mas eles não se importam, fingem que é tudo bandido. Não tem um que morra que não aparece no jornal dizendo que era envolvido. Então é todo mundo.

\section{Considerações finais}

Passados quase 30 anos do fim da ditadura militar, a democracia brasileira ainda enfrenta uma constrangedora realidade. Apesar da consolidação dos direitos políticos, com a participação popular no processo eleitoral, o Estado encontra dificuldades para garantir os direitos sociais e civis de parcela da sociedade. A situação é especialmente crítica quando se trata do provimento de segurança pública e o controle da criminalidade violenta. O serviço policial está no centro deste problema. Não obstante os esforços governamentais com a criação de Planos Nacionais, entre outras iniciativas, para modernizá-las, as Polícias, em especial as Polícias Militares, continuam resistindo às tentativas de modificação de mentalidades e da incorporação de práticas condizentes com os pressupostos democráticos. A consequência disto é que temos Polícias incapazes de responder satisfatoriamente às demandas da sociedade por controle e prevenção da criminalidade, ao mesmo tempo estando elas entre as principais violadoras dos direitos civis dos cidadãos.

Caldeira e Holston sugerem que o Brasil apresenta características de uma disjunctive democracy (Holston, 1999, 2007, 2008; Caldeira, 2000; Holston \& Caldeira, 1998). A expressão serve para classificar democracias emergentes que possuem um sistema eleitoral saudável, mas que são incapazes de fazer com que as instituições de controle social formal, especialmente o aparato de segurança pública e o sistema de justiça, assegurem o respeito aos direitos civis dos seus 
cidadãos de forma universal. De certo, o Brasil se encaixa nesta definição. Como destacaram Adorno (1998) e Kant de Lima (2001), a Carta Constitucional de 1988 provocou a discussão sobre o papel das Polícias e da Justiça como instituições responsáveis por garantir a proteção dos direitos para todos os cidadãos brasileiros, representando um marco na reformulação das diretrizes das Polícias. Todavia, na prática, o que se percebe é que muitos de seus agentes operam a partir da desconsideração dos direitos constitucionais da população pobre do país, guiando-se pela classificação hierárquica da sociedade brasileira. Como aponta Kant de Lima (1995), a prática policial deixa clara a percepção de que o acesso a direitos se relaciona ao enquadramento do indivíduo nos critérios que levam em conta questões econômicas e de status social.

Sem desconsiderar as particularidades que envolvem a cultura policial nos diversos estados brasileiros e as especificidades das localidades onde atuam cotidianamente, não é equivocado afirmar que as insatisfações dos moradores do Pavão-Pavãozinho e do Cantagalo são compartilhadas com os demais moradores de áreas pobres, não apenas do Estado do Rio de Janeiro. ${ }^{15}$ Torturas, detenções violentas, abuso de força e execuções são elencados como procedimentos que marcam as experiências da relação com policiais, representando um desafio aos preceitos constitucionais que garantem o alcance universal dos direitos civis e sociais (Soares, 1996; Human Rights Watch, 2009). Como Cano (2001) argumenta, as violações dos direitos civis por parte de policiais ocorrem com maior frequência contra pessoas que já tiveram seus direitos de ordem socioeconômica anteriormente violados. Os moradores do Cantagalo e do Pavão-Pavãozinho confirmam existir a percepção de que os policiais guiam suas ações a partir de critérios que consideram tanto as questões socioeconômicas como as geográficas.

$\mathrm{O}$ que as narrativas apresentadas aqui parecem indicar de novo é a crescente reivindicação por modificação no tratamento dispensado por policiais e a demanda por reconhecimento da sua condição de sujeitos portadores de direitos. Diversos autores têm apontado que a linguagem dos direitos individuais e de cidadania está se difundindo e adquirindo progressiva legitimidade entre as camadas populares da nossa sociedade (Durham, 1997, 2004; Machado, 2003; Cardoso de Oliveira, 2011a, 2011b). Por sua vez, no que se refere à atuação das instituições públicas e de ONGs, presenciamos uma crescente mobilização acerca de projetos e programas com propostas de "promoção da cidadania" (Mota \& Freire, 2011), numa demonstração de que a linguagem dos direitos consolidouse como legítima na esfera pública. Isto indica que vivemos uma modificação daquela situação descrita por Da Matta (2000), segundo a qual a cidadania e o cidadão eram definidos de forma negativa. 
Mas o que significa afirmar que se têm direitos, na perspectiva dos moradores das favelas tratadas aqui? Certamente suas reclamações encontram respaldo nas normas constitucionais. Afinal de contas, corrupção, violência policial, execuções e adoção de procedimentos que colocam em risco suas vidas e segurança são práticas passíveis de punição legal. Todavia, a centralidade da noção de respeito que pauta as concepções e as demandas por direitos sugere que não se trata de apontar a inobservância dos preceitos constitucionais que garantem o alcance universal dos direitos de cidadania. O respeito de que tanto falam não corresponde ao respeito da norma, mas sim ao respeito à pessoa que, segundo eles, dependendo das suas escolhas, merece ter sua dignidade reconhecida através de tratamento adequado. O direito do qual falam é o direito de receber, por parte dos policiais, tratamento que demonstre, por um lado, respeito, e por outro, preocupação com suas vidas e sua segurança. Trata-se de uma concepção derivada da expectativa pelo reconhecimento daquilo que Cardoso de Oliveira chamou de "substância moral das pessoas dignas" (2011b).

As reflexões de Cardoso de Oliveira (2002, 2013) sobre reconhecimento e dilemas da cidadania brasileira são particularmente interessantes para se compreender a centralidade da noção de respeito nas narrativas dos moradores das duas favelas. Ele sugere que, apesar de a noção de igualdade ocupar um lugar central nas reflexões sobre a efetivação dos direitos, constituindo-se na principal medida para a avaliação da cidadania desde o trabalho de Marshall, a apreciação da sua capilaridade no interior de uma dada sociedade não tem sido capaz de produzir um entendimento satisfatório das demandas contemporâneas por respeito a direitos (2011b). Ou seja, a simples desconsideração do princípio que concebe que todos os cidadãos estão em condições de igualdade, sujeitos aos mesmos deveres e direitos, não é suficiente para se entenderem demandas e insatisfações como as apresentadas neste artigo.

Segundo ele, para compreendê-las, é necessário atentar para a forma como as noções de igualdade, justiça e dignidade articulam-se no contexto das relações sociais conflituosas (Cardoso de Oliveira, 2011a). Em um cenário como este, a noção de dignidade é fundamental, mesmo quando se trata de relações regidas por princípios hierárquicos. Destarte, não é o não compartilhamento de uma percepção mútua de igualdade que fomenta as insatisfações, mas sim a percepção de que sua condição moral não é reconhecida como suficiente para que o sujeito se torne alvo de um tratamento respeitoso que considere sua dignidade. É o que ocorre nas duas favelas. Os procedimentos policiais geram insatisfações e desencadeiam reclamações porque são significados pelos moradores como demonstrações de desrespeito e de desconsideração da sua condição moral. 
Para concluir, gostaria de retomar a discussão sobre a legitimação adquirida pelo discurso dos direitos na esfera pública. ${ }^{16}$ Diversas minorias, como homossexuais, negros, favelados, adeptos de religiões de matriz africana, mulheres etc., têm demandado direitos a partir desta linguagem, indicando sua consolidação nos mais variados segmentos da sociedade brasileira. Todavia, o fato de ser cada vez mais comum ver demandas por direitos serem publicizadas a partir do acionamento discursivo da cidadania, não significa que na sociedade brasileira não vigore mais aquilo que DaMatta chamou de cidadania relacional (2000). Uma coisa é a transformação na espera pública e a legitimidade do discurso dos direitos, outra coisa é o que ocorre no espaço público, onde concepções hierárquicas da sociedade ainda pautam as relações sociais. O acionamento, por parte dos moradores da favela do Pavão-Pavãozinho e da favela do Cantagalo, da condição de trabalhador e de contribuinte como qualificante para a consideração dos seus direitos aponta nesta direção.

Recebido em 06/08/2012

Aceito em 20/01/2013

Marcus Cardoso é Mestre e Doutor em Antropologia Social pelo PPGAS/ DAN/UnB. Pesquisador associado ao Instituto de Estudos Comparados de Administração Institucional de Conflitos (INCT-InEAC) e ao Laboratório de Pesquisa Cidadania, Administração de Conflitos e Justiça (UnB). Atualmente realiza estágio Pós-Doutoral no PPGAS/DAN/UnB, com bolsa do CNPq, e é professor da UNIFAP. 


\section{Notas}

1. Por dimensão simbólica refiro-me às concepções de direitos e justiça que não são passíveis de encapsulamento pela sua dimensão normativa, presente na lei positivada, e que carregam consigo demandas de conteúdo moral que envolvem questões referentes às reivindicações por respeito e reconhecimento da dignidade das pessoas (Cardoso do Oliveira, 2002, 2010).

2. Para saber mais sobre as disputas entre facções rivais nas duas favelas, ver Cardoso (2005).

3. Sigla para Centro Integrado de Ensino Público. Complexos escolares idealizados por Darcy Ribeiro e projetados por Oscar Niemeyer durante a gestão de Leonel Brizola como governador do Estado do Rio de Janeiro.

4. O GPAE era um projeto inspirado na filosofia do policiamento comunitário, instalado nas favelas no ano 2000. Criança Esperança é um projeto social destinado às crianças que se encontram em situação de vulnerabilidade. PAC é a sigla do programa do governo federal que tem como objetivo declarado promover o desenvolvimento econômico e social através de obras de infraestrutura. UPP, por sua vez, é um projeto da Secretaria Estadual de Segurança Pública do Rio de Janeiro, com clara inspiração na filosofia do policiamento comunitário. Seu objetivo declarado é recuperar territórios anteriormente dominados pelo tráfico e/ou milicianos, devolvendo-os aos moradores das favelas. Entre seus procedimentos destaca-se a tentativa de estabelecer aproximação entre policiais e população, além permitir que as outras instituições do Poder Público possam se estabelecer e atuar nessas áreas.

5. Minha inserção nas duas favelas ocorreu em 2001. O ISER - Instituto Superior de Estudos sobre a Religião - interessado em acompanhar a implantação de um projeto da Secretaria Estadual de Segurança Pública, iniciou uma pesquisa intitulada "Violência, Sociabilidade e Espaço Público”, da qual fiz parte. Desde então, a percepção dos moradores das duas favelas sobre a polícia tornou-se objeto do meu interesse. As narrativas apresentadas neste artigo foram obtidas entre os anos de 2001 e 2007. Nos anos de 2001, 2002 e 2004, período que cobre minha graduação e mestrado, estive em campo sempre interessado na forma como os moradores significavam e vivenciavam a presença policial nas duas favelas, assim como o impacto disso no funcionamento do projeto implementado pelo governo do estado. Posteriormente, no ano de 2007, retornei ao campo motivado pela memória dos moradores sobre o projeto, assim como pelas interpretações que elaboravam para explicar o seu fracasso. Durante todos esses anos, o eixo de reflexão girou em volta de questões sobre reclamações da polícia e demandas por respeito a direitos.

6. Como demonstrarei adiante, as queixas não se encerram no apontamento da desconsideração dos princípios constitucionais que garantem seus direitos como cidadãos. Elas 
envolvem uma percepção de desconsideração à pessoa, sujeito moral, e não simplesmente ao indivíduo, portador de direitos universais.

7. "Pessoa de bem" e "movimento" são categorias locais amplamente difundidas e que costumam ser acionadas quando se trata de comparar pessoas e opções dentro das favelas. Envolvem noções de dignidade, moralidade e uma "ética do trabalho". Enquanto "movimento" se refere ao crime organizado local, "pessoa de bem" diz respeito a todos aqueles que não aderiram ao crime, mantendo sua "honra intacta".

8. Na minha tese de doutorado, no capítulo intitulado "O tempo do medo e do desrespeito”, descrevo alguns episódios de violência e abusos cometidos pelo movimento, nos quais os moradores corresponsabilizavam os policiais: casos como o de uma família que se viu obrigada a abandonar sua casa do dia para a noite sem que pudesse retornar para recolher seus pertences; ou de vítimas daquilo que é chamando localmente como "pego para cristo" (quando alguém se torna alvo de implicância e passa a sofrer perseguições de pessoas que pertencem ao grupo criminoso); assédios intimidadores direcionados às mulheres ou a jovens; ou ainda episódios em que ocorre humilhação pública (Cardoso, 2010).

9. Enquanto, normalmente, o corrupção de um representante do Estado é visto como um desvio de conduta, pesquisadores como Das (2004) e Shapiro Anjaria (2011), cada um à sua maneira, demonstraram que a aproximação entre criminosos e agentes do Estado, antes de representar um desvio, compõe, em muitos casos, uma aliança profundamente consolidada que ocorre em espaços comuns de negociação entre chefes do crime e atores governamentais.

10. Cabe destacar que, alguns dias depois, devido à repercussão do ocorrido, os policiais envolvidos tornarem-se objeto de investigação, sendo afastados por ordem de seus superiores.

11. Para saber mais sobre o medo proveniente dos tiroteios em favelas, vale destacar o artigo de Cavalcante, publicado em 2008 sob o título "Tiroteios, legibilidade e espaço urbano".

12. Programa do Governo Municipal, que tinha como objetivo promover ações de urbanização das favelas e que contava com o financiamento do Banco Interamericano de Desenvolvimento.

13. Graças a um acordo com a minha locatária, fiquei isento da conta de TV a cabo, podendo usufruir do serviço como cortesia.

14. Havia um burburinho sobre mais uma projeto de intervenção urbanística, mesmo antes do anúncio oficial do PAC nas duas favelas.

15. Como exemplo, a percepção dos moradores de áreas pobres sobre as instituições policiais da Bahia (Machado \& Noronha, 2002) e de outras favelas do Rio de Janeiro (Machado da Silva \& Leite, 2008) apresenta semelhanças com a visão dos moradores do Pavão-Pavãozinho e Cantagalo. 
16. A distinção que apresento entre arena pública e esfera pública tem como referência a discussão de Cardoso de Oliveira. Arena pública é "o campo das relações situadas fora do contexto doméstico e da intimidade onde as interações sociais efetivamente têm lugar”, enquanto a esfera pública é "o universo discursivo onde normas, projetos e concepções de mundo são publicizados” (2002:12). 


\section{Referências bibliográficas}

ADORNO, S. 1998. "Conflitualidade e violência: reflexões sobre a anomia na contemporaneidade”. Tempo Social - Revista de Sociologia da USP, 10(1):19-47.

CALDEIRA, T. 2000. City of Wall: Crime, segregation, and citizenship in São Paulo. BerkeleyLondon: University of California Press.

CANO, Ignácio. 2001. "Nós e eles: direitos humanos, a polícia e a visão dicotômica da sociedade”. In: Regina Novaes (org.). Direitos Humanos: temas e perspectivas. Rio de Janeiro: MUAD. pp.117-122.

CARDOSO, Marcus. 2010. Como morre um projeto de policiamento comunitário. O caso do Cantagalo e do Pavão-Pavãozinho. Tese de Doutorado, PPGAS, Universidade de Brasília.

. 2005. "Eu finjo que não te vi, você finge que não me vê": uma etnografia sobre a relação entre polícia comunitária, tráfico e população favelada. Dissertação de Mestrado, PPGAS, Universidade de Brasília.

. 2003.“A localização na favela: percepções e práticas do espaço entre católicos do Pavão-Pavãozinho”. Comunicações do ISER, 22 (58):50-61.

CARDOSO DE OLIVEIRA, L.R. 2002. Direito legal e insulto moral: dilemas de cidadania no Brasil, Quebec e EUA. Rio de Janeiro: Relume Dumará.

.2011a. “A dimensão simbólica dos direitos e a análise dos conflitos”. Revista de Antropologia, 53:451-473.

. 2011b. “Concepções de igualdade e cidadania”. Contemporânea Revista de Sociologia da UFSCar, 1:35-48.

. 2010. “Concepções de igualdade e (des)igualdades no Brasil (uma proposta de pesquisa)”. In: R. Kant de Lima; L. Eilbaum \& L. Pires (orgs.).Conflitos, direitos e moralidades em perspectiva comparada. Vol. 1. Rio de Janeiro: Garamond. pp.19-36.

2013. "Equality, Dignity and Fairness: Brazilian Citizenship in Comparative Perspective”. Critique of Anthropology, 33(2):131-145.

DAS, Veena. 2004. “The Signature of the State: the Paradox of IIlegibility”. In: V. Das \& D. Poole (orgs.). Anthropology in the Margins of the State. Santa Fe, NM: School of American Research Press. pp. 225-252.

DAMATTA, Roberto. 2000. "Cidadania - A questão da cidadania num universo relacional”. In: R. Da Matta. A casa e a rua: espaço, cidadania, mulher e morte no Brasil. Rio de Janeiro: Rocco. pp. 65-95. 
DURHAM, E. 1997. "A pesquisa antropológica com populações urbanas: problemas e perspectivas”. In: R. Cardoso (org.). A aventura antropológica. São Paulo: Paz e Terra. pp. 17-38.

GEERTZ, Clifford. 2002. O saber local: novos ensaios em antropologia interpretativa. Petrópolis: Editora Vozes.

HOLSTON, J. 1999. "Spaces of insurgent citizenship". In: J. Holston (org.). Cities and citizenship. Durham-London: Duke University Press. pp.155-177.

. 2008. Insurgent citizenship: disjunctions of democracy and modernity in Brazil. Princeton: Princeton University Press.

2007. "Citizenship in Disjunctive democracies”. In: J. Tulchin \& M. Ruthemburg (orgs.).Citizenship in Latin American. London: Lynne Reinner Publishers. pp.75-95

HOLSTON, J. \& CALDEIRA, T. 1998. "Democracy, law, and violence: disjunctive of brazilian citizenship”. In: F. Aguero \& J. Stark (orgs.). Fault lines of democracy in post-transition Latin America. Miami: North-South Center.

HUMAN RIGHTS WATCH. 2009. Força Letal: Violência policial e segurança pública no Rio de Janeiro e São Paulo. USA: HRW.

KANT DE LIMA, Roberto. 1995. A polícia da cidade do Rio de Janeiro: seus dilemas e paradoxos. Rio de Janeiro: Editora Forense.

2001.“Espaço público, sistemas de controle social e práticas policiais: o caso brasileiro em uma perspectiva comparada”. In: Regina Novaes (org.). Direitos Humanos: temas e perspectivas. Rio de Janeiro: MUAD. pp. 94-111.

MACHADO, Eduardo \& NORONHA, Ceci. 2002. "A polícia dos pobres: violência policial em classes populares urbanas". Sociologias, 4 (7):188-22.

MACHADO, Lia Z. 2003. "Entre o inferno e o paraíso. Saúde, direitos e conflitualidades”. Série Antropologia 342, Brasília, UnB.

MACHADO DA SILVA, L.A. \& LEITE, Marcia. 2008. "Violência, crime e polícia: o que os favelados dizem quando falam desses temas?”. In: L.A. Machado da Silva (org.). Vida sob cerco: violência e rotina nas favelas do Rio de Janeiro. Rio de Janeiro: Nova Fronteira. pp. 47-76.

MOTA, F. R.\& FREIRE, L. L. 2011. “O direito de ter ou não ter direitos: a dimensão moral do reconhecimento na promoção de cidadania”. Contemporânea Revista de Sociologia da UFSCar, 1:127-145. 
RIBEIRO, M. 2003. “O morro: Territórios em construção”. Comunicações do ISER, 22 (58):45-50.

SHAPIRO ANJARIA, J. 2011. "Ordinary States: Everyday Corruption and the Politics of Space in Mumbai”. American Ethnologist, 38(1):58-72.

SETH, M. 1985. Pavão-Pavãozinho/Cantagalo, o Povo Sobe no Governo Brizola. Rio de Janeiro: Secretaria de Estado do Trabalho e da Habitação.

SOARES, Luiz Eduardo. 1996. “Segurança Pública: Presente e Futuro”. Estudos Avançados, 20:91-106.

ZALUAR, Alba. 1985. A máquina e a revolta. São Paulo: Brasiliense. 1994. Condomínio do diabo. Rio de Janeiro: Revan/UFRJ. . 2010. "Youth, drug traffic and hyper-masculinity in Rio de Janeiro". Vibrant, 7:7-27. 


\section{Resumo}

Ainda que determinadas insatisfações provenientes do tratamento dispensado por agentes do Estado expressem demandas por respeito aos direitos de cidadania, configurando-se desta forma numa demanda por consideração dos aspectos normativos do Direito, elas só podem ser devidamente compreendidas se atentarmos para sua dimensão simbólica. Foi disto que me dei conta acompanhando a relação entre os policiais militares e os moradores de duas favelas no Rio de Janeiro. As narrativas destes moradores, ao mesmo tempo em que apresentam diversas queixas em relação aos policiais, revelam concepções de direitos e justiça baseados em categorias locais. Através destas categorias, os moradores falam de suas expectativas sobre o desejo de mudança das relações com a polícia e demandas por respeito e reconhecimento dos seus direitos.

Palavras-chave: Demandas por reconhecimento, concepções de direitos, favelas, violência policial

\section{Abstract}

Although certain discontents from the treatment by state agents express demands for respect for the rights of citizenship, becoming thus a demand for consideration of the normative aspects of law, they can only be properly understood if we look at their symbolism. That's what I realized watching the relationship between police officers and residents in two favelas in Rio de Janeiro. The narratives of these residents, while presenting several complaints against the police, reveal conceptions of rights and justice based on local categories. Through these categories the residents talk about their expectations about the desire for change in relations with the police and demands for respect and recognition of their rights.

Keywords: Demands for recognition, conceptions of rights, favelas, police violence 